\title{
Estrutura e florística de dois fragmentos de florestas aluviais no Vale do rio Paraíba do Sul, SP, Brasil ${ }^{1}$
}

\author{
Felipe de Alva Escuredo D'Orazio ${ }^{2,3}$ e Eduardo Luís Martins Catharino ${ }^{2}$
}

Recebido: 26.06.2013; aceito: 24.09.2013

\begin{abstract}
Structure and floristics of two alluvial forests fragments in the Valley of Paraiba do Sul river, São Paulo State, Brazil). The Valley of Paraiba do Sul River is marked by the suppression of river-margin native vegetation. The flora and the structure of forests fragments located in São José dos Campos (Eugênio de Melo - EM) and Tremembé (TR) have been characterized to obtain a list of tree species recommended for recovery of degraded floodplain areas. Each area received two plots $(50 \times 20 \mathrm{~m})$ with the criteria of trees with breast diameter height $(1.30 \mathrm{~m}) \geq 5 \mathrm{~cm}$. The data interpretation was based on usual phytosociology parameter and multivariate analyzes, as well as the Shannon diversity index (H') and Pielou evenness (E). The phytophysionomy in TR is more heterogeneous and complex compared to EM, whose homogeneity is expressed by the predominance of Sebastiania commersoniana and Alchornea triplinervia.
\end{abstract}

Key words: gallery forest recovery, riparian zone, swamp forest

RESUMO - (Estrutura e florística de dois fragmentos de florestas aluviais no Vale do rio Paraíba do Sul, SP, Brasil). O Vale do rio Paraíba do Sul pode ser caracterizado pela supressão intensa de suas formações vegetais nativas adjacentes. Este trabalho buscou caracterizar a estrutura e a flora de fragmentos florestais remanescentes localizados em São José dos Campos (Eugênio de Melo - EM) e Tremembé (TR) e obter a listagem de espécies florestais de várzea inundável recomendada para recuperação de áreas degradadas da região. Cada área recebeu duas parcelas $(50 \times 20 \mathrm{~m})$ onde foram incluídas árvores com diâmetro a $1,30 \mathrm{~m}$ de altura do solo $\geq 5 \mathrm{~cm}$. Para a interpretação dos dados foram utilizados os parâmetros fitossociológicos usuais e análises multivariadas, assim como o índice de diversidade de Shannon (H') e de equabilidade de Pielou (E). A fitofisionomia em TR é mais heterogênea e complexa comparada à EM, cuja homogeneidade é expressa pelo predomínio de populações de Sebastiania commersoniana e Alchornea triplinervia.

Palavras-chave: floresta paludosa, recuperação de mata ciliar, zona ripária

\section{Introdução}

As formações vegetais do território paulista são compostas fundamentalmente por espécies do domínio Atlântico e do Cerrado. O valor referente à cobertura original da Mata Atlântica no Estado de São Paulo varia entre $81,8 \%$ e $67,4 \%$, com a área remanescente de $7,64 \%$ a $23,35 \%$ (SMA 1999 , Campanili \& Schäffer 2010). Com relação ao Cerrado, sua área original no Estado foi de aproximadamente 15,4\%, restando, atualmente, menos de $1 \%$ da sua distribuição original (Siqueira \& Durigan 2007). Por garantir umidade mesmo em climas mais secos, as florestas que margeiam corpos d'água atuam como abrigo e no incremento da conectividade desses domínios vegetais, formando mosaicos compostos por espécies das formações circundantes e/ou que apresentem capacidade de suportar períodos prolongados de inundação (Rodrigues \& Nave 2001). Atualmente, mais de um milhão de hectares das áreas marginais dos cursos d'água do Estado de São Paulo deveriam apresentar vegetação em recuperação (Campanili \& Schäffer 2010).

A região que abrange os municípios de Jacareí, São José dos Campos, Caçapava, Taubaté, Tremembé e Pindamonhangaba, localizados na Bacia hidrográfica do médio vale superior do rio Paraíba do Sul, é considerada uma das maiores fornecedoras de areia para construção civil do país. O maior problema ambiental enfrentado pelo poder público local é o

1. Parte de Dissertação de Mestrado do primeiro Autor, Programa de Pós-Graduação em Biodiversidade Vegetal e Meio Ambiente

2. Instituto de Botânica, Caixa Postal 68041, 04045-972 São Paulo, SP, Brasil

3. Autor para correspondência: felipedorazio@bol.com.br 
impacto causado pelas mineradoras sobre a vegetação de várzea e/ou ripária (Batista et al. 2010). Para o exercício dessa atividade exige-se o reflorestamento como medida compensatória do impacto causado (São Paulo 1999); no entanto, a seleção das espécies para plantios é muitas vezes aleatória, incluindo espécies exóticas ou naturais de outras formações vegetais.

Desta forma, este trabalho objetivou: 1) caracterizar a composição florística e estrutural da vegetação arbórea de várzeas aluviais do rio Paraíba do Sul; 2) verificar diferenças entre composição e estrutura de duas áreas sob mesmas condições de alagamento, distantes entre si e de diferentes fisionomias; e 3) identificar as principais espécies para reflorestamento compensatório na região do Vale do Paraíba do Sul.

\section{Material e métodos}

A vegetação da região do vale do Paraíba do Sul é composta por Florestas Estacional e Ombrófila, além de Savanas (Cerrado) e ecossistemas de transição (Hueck 1972). Os fragmentos analisados, apesar de peculiares, foram aqui designados como diferentes trechos da Floresta Ombrófila Densa Aluvial (IBGE 1992), devido à fitofisionomia predominante e pedogênese (gleissolos melânicos) (Moura et al. 2006). O clima na região do Vale do Paraíba pode ser classificado como temperado úmido de verões quentes (Cwa), com média anual de precipitação de $1.350 \mathrm{~mm}$ e temperatura de $20^{\circ} \mathrm{C}$ (Valladares et al. 2004, CEPAGRI 2011).

$\mathrm{O}$ estudo foi desenvolvido em fragmentos de florestas aluviais naturais localizados em duas áreas na várzea inundável do médio vale superior do rio Paraíba do Sul com período de alagamento observado entre os meses de novembro a março, em ambas as áreas. A área de Eugênio de Melo (EM), distrito do município de São José dos Campos, apresenta dois fragmentos que distam $15 \mathrm{~m}$ entre si. $\mathrm{O}$ primeiro (EM1) localizado nas coordenadas $23^{\circ} 07^{\prime} 34,15^{\prime \prime S}$ e $45^{\circ} 47^{\prime} 06,56 " \mathrm{~W}$, e o segundo (EM2) localizado nas coordenadas $23^{\circ} 07^{\prime} 27,87^{\prime \prime} \mathrm{S}$ e $45^{\circ} 47^{\prime} 20,10^{\prime \prime} \mathrm{W}$, ambos a cerca de $550 \mathrm{~m}$ de altitude. A outra área amostrada encontra-se no município de Tremembé (TR) e apresenta um fragmento localizado nas coordenadas $22^{\circ} 58^{\prime} 40,94^{\prime \prime} \mathrm{S}$ e $45^{\circ} 38^{\prime} 05,43^{\prime \prime} \mathrm{W}$, a cerca de $545 \mathrm{~m}$ de altitude.

Foram instaladas quatro parcelas de $50 \times 20 \mathrm{~m}$ $\left(1.000 \mathrm{~m}^{2}\right)$, duas em EM (uma em cada fragmento EM1 e EM2) e duas em TR (no mesmo fragmento -
TR1 e TR2), subdivididas em parcelas menores de $10 \times 10 \mathrm{~m}\left(100 \mathrm{~m}^{2}\right)$, totalizando uma área amostral de 0,4 ha. No interior dessas parcelas foram amostrados os indivíduos arbóreos que apresentaram DAP (diâmetro a $1,30 \mathrm{~m}$ de altura do solo) $\geq 5 \mathrm{~cm}$.

Os parâmetros fitossociológicos, além do índice de diversidade de Shannon $\left(\mathrm{H}^{\prime}\right)$ e de equabilidade de Pielou (J), foram obtidos pelo Programa FITOPAC 2.1 (Shepherd 2002). A técnica de ordenação utilizada foi a análise de coordenadas principais (PCO), por tratar-se de uma análise indireta de gradientes baseada em uma matriz de distância; e o método de agrupamento para definir grupos com diferentes graus de similaridade foi o agrupamento por médias não ponderadas (UPGMA), calculado pelo coeficiente de Bray-Curtis por tratar-se de matriz de abundância e que obteve maior valor do coeficiente de correlação cofenética (Felfilli et al. 2011). Para a caracterização das comunidades analisadas através de espécies indicadoras foi utilizado o método de classificação objetiva TWINSPAN.

A identificação do material botânico coletado foi efetuada com base na consulta de literatura especializada, consulta a especialistas e na comparação de exsicatas do herbário Maria Eneida P. K. Fidalgo (SP), Instituto de Botânica, onde foram depositados os materiais férteis. Os nomes científicos e relações filogenéticas seguem o sistema de classificação APGIII, e a confirmação dos nomes científicos e sinonímias botânicas basearam-se na listagem da Flora do Brasil (Forzza et al. 2010).

Para a classificação das categorias sucessionais das espécies arbóreas foi utilizado o Anexo 1 da resolução SMA 08/2008 (São Paulo 2008); para a classificação das síndromes de dispersão utilizaram-se os critérios de Pijl (1982); e para a descrição dos hábitos das espécies coletadas (arbóreo, arbustivo, liana, epífita ou erva) utilizou-se Dansereau (1957).

\section{Resultados e Discussão}

Foram listadas no levantamento florístico conjunto (Eugênio de Melo e Tremembé) 89 espécies de 70 gêneros (excluindo três indeterminadas) distribuídos em 37 famílias e duas indeterminadas (tabela 1).

As espécies arbóreas ocorrentes em ambos os fragmentos, além de representarem 19\% do total das árvores listadas, dividem-se pela categoria sucessional em $55 \%$ de espécies não pioneiras e $45 \%$ de pioneiras; e 73\% dessas espécies arbóreas apresentam síndrome 
Tabela 1. Listagem florística de Eugênio de Melo (São José dos Campos) e Tremembé na região da planície aluvial do médio vale superior do rio Paraíba do Sul, SP, Brasil. EM: Eugênio de Melo; TR: Tremembé; GE: grupo ecológico; P: pioneira; NP: não-pioneira; EX: exótica; SD: síndrome de dispersão; ANE: anemocórica; AUT: autocórica; ZOO: zoocórica; H: hábito. Arb: arbusto; Arv: árvore; Epif: epífita; Erv: erva; Trep: trepadeira; CA: categoria de ameaça (São Paulo 2008); QA: quase ameaçada; Npop: nome popular.

Table 1. Floristic list of Eugênio de Melo (São José dos Campos) and Tremembé in the alluvial floodplain region of middle valley of Paraíba do Sul River, São Paulo State, Brazil. EM: Eugênio de Melo; TR: Tremembé; GE: ecological group; P: pionner; NP: non-pionner; EX: exotic; SD: dispersion syndrome; ANE: anemochory; AUT: autochory; ZOO: zoochory; H: habit; Arb: bush; Arv: tree; Epif: epiphyte; Erv: herb; Trep: liana; CA: threat category (São Paulo 2008); QA: near threatened; Npop: popular name.

\begin{tabular}{|c|c|c|c|c|c|c|c|}
\hline Família/espécie & EM & TR & GE & $\mathrm{SD}$ & $\mathrm{H}$ & $\mathrm{CA}$ & Npop \\
\hline \multicolumn{8}{|l|}{ Annonaceae } \\
\hline Annona cacans Warm. & & $\mathrm{x}$ & $\mathrm{P}$ & $\mathrm{ZOO}$ & Arv & & araticum-cagão \\
\hline Xylopia emarginata Mart. & & $\mathrm{x}$ & NP & $\mathrm{ZOO}$ & Arv & & pindaíba d'água \\
\hline Xylopia ochrantha Mart. & & $\mathrm{x}$ & NP & $\mathrm{ZOO}$ & Arv & & pindaíba \\
\hline \multicolumn{8}{|l|}{ Apocinaceae } \\
\hline Condylocarpon isthmicum (Vell.) A. DC. & & $\mathrm{x}$ & & ANE & Trep & & tênia \\
\hline Malouetia cestroides (Nees) Müll. Arg. & & $\mathrm{x}$ & $\mathrm{P}$ & ANE & Arv & & leiteiro \\
\hline \multicolumn{8}{|l|}{ Araliaceae } \\
\hline Dendropanax cuneatus (DC) Decne. \& Planch. & & $\mathrm{x}$ & $\mathrm{P}$ & $\mathrm{ZOO}$ & Arv & & maria-mole \\
\hline \multicolumn{8}{|l|}{ Arecaceae } \\
\hline Acrocomia aculeata (Jacq.) Lood. ex Mart. & & $\mathrm{x}$ & NP & $\mathrm{ZOO}$ & Arv & & macaúba \\
\hline Syagrus romanzoffiana (Cham.) Glassman & & $\mathrm{x}$ & NP & $\mathrm{ZOO}$ & Arv & & jerivá \\
\hline \multicolumn{8}{|l|}{ Bignoniaceae } \\
\hline Fridericia speciosa Mart. & & $\mathrm{x}$ & & ANE & Trep & & \\
\hline Jacaranda sp. & $\mathrm{x}$ & & & ANE & Arv & & \\
\hline Amphilophium sp. & & $\mathrm{x}$ & & ANE & Trep & & \\
\hline Handroanthus umbellatus (Sond.) Sandwith & $\mathrm{x}$ & $\mathrm{x}$ & NP & ANE & Arv & & ipê-amarelo-do-brejo \\
\hline \multicolumn{8}{|l|}{ Bromeliaceae } \\
\hline Aechmea distichantha Lem. & $\mathrm{x}$ & & & $\mathrm{ZOO}$ & Epif & & gravatá \\
\hline Nidularium innocentii Lem. & & $\mathrm{x}$ & & $\mathrm{ZOO}$ & Epif & & nidulário \\
\hline Nidularium procerum Lindm. & & $\mathrm{x}$ & & $\mathrm{ZOO}$ & Epif & & nidulário \\
\hline Vriesea incurvata Gaudich. & & $\mathrm{x}$ & & ANE & Epif & & bromélia \\
\hline Tillandsia geminiflora Brogn. & & $\mathrm{x}$ & & ANE & Epif & & bromélia \\
\hline \multicolumn{8}{|l|}{ Cactaceae } \\
\hline Pereskia aculeata Mill. & & $\mathrm{x}$ & & $\mathrm{ZOO}$ & Trep & & ora-pro-nobis \\
\hline \multicolumn{8}{|l|}{ Celastraceae } \\
\hline Maytenus evonymoides Reissek & & $\mathrm{x}$ & NP & $\mathrm{ZOO}$ & Arv & & cafezinho \\
\hline \multicolumn{8}{|l|}{ Commelinaceae } \\
\hline Commelina diffusa Burm.f. & & $\mathrm{x}$ & & $\mathrm{ZOO}$ & Erv & & trapoeraba \\
\hline \multicolumn{8}{|l|}{ Convolvulaceae } \\
\hline Evolvulus sp. & & $\mathrm{x}$ & & AUT & Trep & & \\
\hline \multicolumn{8}{|l|}{ Euphorbiaceae } \\
\hline Alchornea triplinervia (Spreng.) Müll. Arg. & $\mathrm{x}$ & $\mathrm{x}$ & $\mathrm{P}$ & $\mathrm{ZOO}$ & Arv & & tapiá \\
\hline Croton urucurana Baill. & $\mathrm{x}$ & & $\mathrm{P}$ & AUT & Arv & & sangra-d'água \\
\hline $\begin{array}{l}\text { Sebastiania commersoniana (Baill.) L.B. Smith } \\
\text { R.J. Downs }\end{array}$ & $\mathrm{x}$ & $\mathrm{x}$ & $\mathrm{P}$ & AUT & Arv & & branquilho \\
\hline
\end{tabular}


Tabela 1 (continuação)

\begin{tabular}{|c|c|c|c|c|c|c|c|}
\hline Família/espécie & EM & $\mathrm{TR}$ & GE & SD & $\mathrm{H}$ & $\mathrm{CA}$ & Npop \\
\hline \multicolumn{8}{|l|}{ Fabaceae } \\
\hline Anadenanthera colubrina (Vell.) Brenan & & $\mathrm{x}$ & NP & AUT & Arv & & angico-branco \\
\hline Andira anthelmia (Vell.) J.F. Macbr. & & $\mathrm{x}$ & NP & $\mathrm{ZOO}$ & Arv & & garacuí \\
\hline Copaifera langsdorffii Desf. & & $\mathrm{x}$ & NP & $\mathrm{ZOO}$ & Arv & & copaíba \\
\hline Copaifera trapezifolia Hayne & & $\mathrm{x}$ & NP & $\mathrm{ZOO}$ & Arv & & pau-óleo \\
\hline Erythrina crista-galli L. & $\mathrm{x}$ & $\mathrm{x}$ & $\mathrm{P}$ & AUT & Arv & & corticeira-do-banhado \\
\hline Inga subnuda subsp. luschnathiana (Benth.) T.D. Penn. & & $\mathrm{x}$ & $\mathrm{P}$ & $\mathrm{ZOO}$ & Arv & & ingá \\
\hline Inga vera subsp. affinis (DC.) T.D. Penn. & $\mathrm{x}$ & $\mathrm{x}$ & $\mathrm{P}$ & $\mathrm{ZOO}$ & Arv & & ingá-do-brejo \\
\hline Inga vulpina Mart. ex Benth. & & $\mathrm{x}$ & $\mathrm{P}$ & $\mathrm{ZOO}$ & Arv & & ingá-peludo \\
\hline Pterocarpus rohrii Vahl & & $\mathrm{x}$ & NP & ANE & Arv & & aldrago-miúdo \\
\hline Zollernia ilicifolia Vogel & & $\mathrm{x}$ & NP & $\mathrm{ZOO}$ & Arv & & zolernia \\
\hline \multicolumn{8}{|l|}{ Lauraceae } \\
\hline Nectandra nitidula Nees & $\mathrm{x}$ & & NP & $\mathrm{ZOO}$ & Arv & & canela-amarela \\
\hline \multicolumn{8}{|l|}{ Lecythidaceae } \\
\hline Cariniana estrellensis (Raddi) Kuntze & & $\mathrm{x}$ & NP & ANE & Arv & QA & jequitibá-branco \\
\hline \multicolumn{8}{|l|}{ Magnoliaceae } \\
\hline Magnolia ovata (A.St.-Hil.) Spreng. & & $\mathrm{x}$ & NP & $\mathrm{ZOO}$ & Arv & & pinha-do-brejo \\
\hline \multicolumn{8}{|l|}{ Malpighiaceae } \\
\hline Heteropterys nitida (Lam.) DC. & & $\mathrm{x}$ & & ANE & Trep & & \\
\hline Heteropterys pteropetala A. Juss. & $\mathrm{x}$ & $\mathrm{x}$ & & ANE & Trep & & \\
\hline Niedenzuella acutifolia (Cav.) W.R.Anderson & & $\mathrm{x}$ & & ANE & Arb & & \\
\hline \multicolumn{8}{|l|}{ Malvaceae } \\
\hline Pseudobombax grandiflorum (Cav.) A. Robyns & & $\mathrm{x}$ & NP & ANE & Arv & & embiruçu-da-mata \\
\hline \multicolumn{8}{|l|}{ Melastomataceae } \\
\hline Miconia ibaguensis (Bonpl.) Triana & $\mathrm{x}$ & & & $\mathrm{ZOO}$ & Arb & & quaresma-gurita \\
\hline Miconia paucidens DC. & & $\mathrm{x}$ & & $\mathrm{ZOO}$ & Arb & & \\
\hline Miconia sp. & & $\mathrm{x}$ & & $\mathrm{ZOO}$ & Arb & & \\
\hline \multicolumn{8}{|l|}{ Meliaceae } \\
\hline Guarea macrophylla Vahl & & $\mathrm{x}$ & NP & $\mathrm{ZOO}$ & Arv & QA & marinheiro-do-brejo \\
\hline Trichilia emarginata C. DC. & & $\mathrm{x}$ & NP & $\mathrm{ZOO}$ & Arv & QA & catiguá-vermelho \\
\hline \multicolumn{8}{|l|}{ Moraceae } \\
\hline Brosimum gaudichaudii Tréc. & & $\mathrm{x}$ & NP & $\mathrm{ZOO}$ & Arv & QA & maminha-cadela \\
\hline Sorocea bonplandii (Baill.) W.C. Burger & & $\mathrm{x}$ & NP & $\mathrm{ZOO}$ & Arv & & cincho \\
\hline \multicolumn{8}{|l|}{ Myrtaceae } \\
\hline Eugenia brevistyla D. Legrand & & $\mathrm{x}$ & & $\mathrm{ZOO}$ & Arv & & guamirim \\
\hline Eugenia dodonaefolia Cambess. & & $\mathrm{x}$ & NP & $\mathrm{ZOO}$ & Arv & & eugenia \\
\hline Eugenia florida DC. & $\mathrm{x}$ & $\mathrm{x}$ & NP & $\mathrm{ZOO}$ & Arv & & pitanga-preta \\
\hline Eugenia myrcianthes Nied. & & $\mathrm{x}$ & NP & $\mathrm{ZOO}$ & Arv & & pessegueiro-do-mato \\
\hline Eugenia platysema $\mathrm{O}$. Berg & & $\mathrm{x}$ & NP & $\mathrm{ZOO}$ & Arv & & \\
\hline Eugenia pluriflora DC. & & $\mathrm{x}$ & NP & $\mathrm{ZOO}$ & Arv & & pitanga-verde \\
\hline Eugenia sp. & & $\mathrm{x}$ & & $\mathrm{ZOO}$ & Arv & & \\
\hline Myrcia multiflora (Lam.) DC. & $\mathrm{x}$ & $\mathrm{x}$ & NP & $\mathrm{ZOO}$ & Arv & & cambuí \\
\hline
\end{tabular}


Tabela 1 (continuação)

\begin{tabular}{|c|c|c|c|c|c|c|c|}
\hline Família/espécie & EM & TR & GE & SD & $\mathrm{H}$ & $\mathrm{CA}$ & Npop \\
\hline Myrciaria floribunda (H.West ex Willd.) O. Berg & & $\mathrm{x}$ & $\mathrm{P}$ & $\mathrm{ZOO}$ & Arv & & cambuizinho \\
\hline Syzygium jambos (L.) Alston & & $\mathrm{x}$ & EX & $\mathrm{ZOO}$ & Arv & & jambeiro \\
\hline Myrtaceae sp. & & $\mathrm{x}$ & & $\mathrm{ZOO}$ & Arv & & \\
\hline \multicolumn{8}{|l|}{ Nyctaginaceae } \\
\hline Neea pendulina Heimerl & & $\mathrm{x}$ & NP & $\mathrm{ZOO}$ & Arv & & \\
\hline Guapira opposita (Vell.) Reitz & & $\mathrm{x}$ & NP & $\mathrm{ZOO}$ & Arv & & flor-de-pérola \\
\hline \multicolumn{8}{|l|}{ Ochnaceae } \\
\hline Ouratea parviflora (A. DC.) Baill. & $\mathrm{x}$ & & & $\mathrm{ZOO}$ & Arb & & batiputá \\
\hline Ouratea semiserrata (Mart. ex Nees) Engl. & & $\mathrm{x}$ & NP & $\mathrm{ZOO}$ & Arv & & castanheira \\
\hline \multicolumn{8}{|l|}{ Onagraceae } \\
\hline Ludwigia sericea (Cambess.) H. Hara & & $\mathrm{x}$ & & AUT & Erv & & cruz-de-malta \\
\hline \multicolumn{8}{|l|}{ Passifloraceae } \\
\hline Passiflora cf. pohlii Mast. & & $\mathrm{x}$ & & $\mathrm{ZOO}$ & Trep & & maracujazinho \\
\hline \multicolumn{8}{|l|}{ Picramniaceae } \\
\hline Picramnia sellowii Planch. & $\mathrm{x}$ & $\mathrm{x}$ & NP & $\mathrm{ZOO}$ & Arv & & cedrinho \\
\hline \multicolumn{8}{|l|}{ Piperaceae } \\
\hline Piper sp. & & $\mathrm{x}$ & & $\mathrm{ZOO}$ & Erv & & \\
\hline \multicolumn{8}{|l|}{ Polygalaceae } \\
\hline $\begin{array}{l}\text { Securidaca rivinifolia A. St.-Hil. \& Moq. var. } \\
\text { rivinifolia } \\
\text { Rubiaceae }\end{array}$ & $\mathrm{x}$ & $\mathrm{x}$ & & ANE & Trep & & ingá-sapo \\
\hline Amaioua intermedia Mart. ex Schult. \& Schult. f. & & $\mathrm{x}$ & NP & $\mathrm{ZOO}$ & Arv & & marmelada \\
\hline Coffea arabica $\mathrm{L}$. & & $\mathrm{x}$ & EX & $\mathrm{ZOO}$ & Arb & & cafeeiro \\
\hline Ixora brevifolia Benth. & & $\mathrm{x}$ & NP & $\mathrm{ZOO}$ & Arv & & \\
\hline Palicourea marcgravii A. St.-Hil & $\mathrm{x}$ & & & $\mathrm{ZOO}$ & Arb & & erva-de-rato \\
\hline Posoqueria latifolia (Rudge) Roem. \& Schult. & & $\mathrm{x}$ & NP & $\mathrm{ZOO}$ & Arv & & laranja-de-macaco \\
\hline Psychotria vellosiana Benth. & $\mathrm{x}$ & & & $\mathrm{ZOO}$ & Arb & & casca-d'anta \\
\hline \multicolumn{8}{|l|}{ Sapindaceae } \\
\hline Matayba elaeagnoides Radlk. & & $\mathrm{x}$ & NP & $\mathrm{ZOO}$ & Arv & & camboatã-branco \\
\hline Matayba juglandiflora (Camb.) Radlk. & & $\mathrm{x}$ & NP & $\mathrm{ZOO}$ & Arv & & camboatã-branco \\
\hline Paullinia micrantha Cambess. & & $\mathrm{x}$ & & $\mathrm{ZOO}$ & Trep & & \\
\hline Serjania sp. & & $\mathrm{x}$ & & ANE & Trep & & \\
\hline \multicolumn{8}{|l|}{ Sapotaceae } \\
\hline Chrysophyllum marginatum (Hook. \& Arn.) Radlk. & $\mathrm{x}$ & $\mathrm{x}$ & NP & $\mathrm{ZOO}$ & Arv & QA & aguaí \\
\hline Ecclinusa ramiflora Mart. & & $\mathrm{x}$ & NP & $\mathrm{ZOO}$ & Arv & & açá \\
\hline \multicolumn{8}{|l|}{ Siparunaceae } \\
\hline Siparuna guianensis Aubl. & & $\mathrm{x}$ & NP & $\mathrm{ZOO}$ & Arv & & siparuna \\
\hline \multicolumn{8}{|l|}{ Smilacaceae } \\
\hline Smilax campestris Griseb. & & $\mathrm{x}$ & & $\mathrm{ZOO}$ & Trep & & salsaparilha \\
\hline \multicolumn{8}{|l|}{ Solanaceae } \\
\hline Solanum sp. & & $\mathrm{x}$ & & $\mathrm{ZOO}$ & Erv & & \\
\hline \multicolumn{8}{|l|}{ Urticaceae } \\
\hline Cecropia pachystachya Tréc. & $\mathrm{x}$ & $\mathrm{x}$ & $\mathrm{P}$ & $\mathrm{ZOO}$ & Arv & & embaúba \\
\hline
\end{tabular}


Tabela 1 (continuação)

\begin{tabular}{|c|c|c|c|c|c|c|c|}
\hline Família/espécie & EM & TR & GE & SD & $\mathrm{H}$ & $\mathrm{CA}$ & Npop \\
\hline Coussapoa microcarpa (Schott) Rizzini & $\mathrm{x}$ & $\mathrm{x}$ & NP & $\mathrm{ZOO}$ & Arv & & figueira-mata-pau \\
\hline \multicolumn{8}{|l|}{ Vitaceae } \\
\hline Cissus sp. & & $\mathrm{x}$ & & $\mathrm{ZOO}$ & Trep & & \\
\hline \multicolumn{8}{|l|}{ Vochysiaceae } \\
\hline Qualea grandiflora Mart. & & $\mathrm{x}$ & NP & ANE & Arv & & pau-terra \\
\hline \multicolumn{8}{|l|}{ INDETERMINADA } \\
\hline Indeterminada 1 & & $\mathrm{x}$ & & & Arv & & \\
\hline Indeterminada 2 & & $\mathrm{x}$ & & & Trep & & \\
\hline
\end{tabular}

de dispersão zoocórica, $18 \%$ autocórica e 9\% anemocórica, critérios relevantes para seleção de espécies em plantios homogêneos de recuperação (Martins 2001).

Cariniana estrellensis, Brosimum gaudichaudii, Chrysophyllum marginatum, Guarea macrophylla e Trichilia emarginata são espécies classificadas como quase ameaçadas no Estado de São Paulo (São Paulo 2008) e que, com exceção das duas primeiras, já haviam sido coletadas nas proximidades dos fragmentos (HUEFS, MBM, SPSF 2012). Essas informações fundamentam a inclusão dessas espécies em listagens para o plantio e recuperação de áreas próximas dos fragmentos analisados.

O padrão de concentração relativa de espécies pela síndrome de dispersão predominantemente zoocórica, característico em florestas tropicais e subtropicais de climas úmidos e com fraca estacionalidade pluvial (Budke et al. 2005, Giehl et al. 2007, Yamamoto et al. 2007), manteve-se entre as áreas (figura 1), sendo mais abundante em Tremembé.

A zoocoria, além de implementar a riqueza e complexidade trófica da comunidade, também proporciona a distribuição espacial mais heterogênea das sementes devido ao comportamento animal (Giehl et al. 2007, Yamamoto et al. 2007). Fragmentos associados a planícies aluviais e depressões inundáveis garantem a atratabilidade da fauna pela disposição de água e proteção contra o fogo, expressando uma estreita conexão entre as florestas aluviais e a fauna associada (Stefanello et al. 2010).

Com relação aos valores de abundância por espécie para cada síndrome de dispersão por área, nota-se o aumento no valor da autocoria em EM, que pode estar relacionado a diferentes estádios sucessionais e níveis de complexidade dessas comunidades (Almeida et al. 2008). A alta densidade absoluta de Sebastiania commersoniana, em ambas
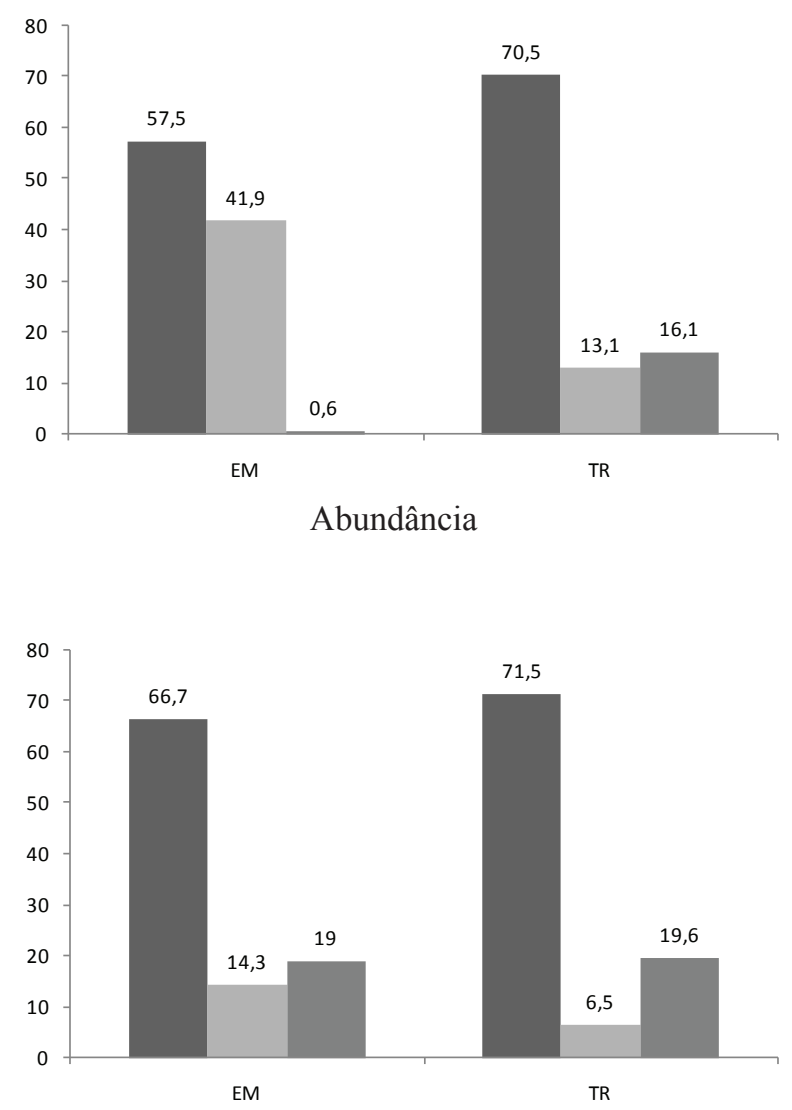

Espécies

Figura 1. Porcentagem em relação ao número de espécies (todos os hábitos) pela síndrome dispersão e porcentagem em relação à abundância de indivíduos arbóreos das amostragens fitossociológicas pela síndrome dispersão para cada área amostrada, SP, Brasil. EM: Eugênio de Melo; TR: Tremembé; ZOO: zoocórica; ANE: anemocórica; AUT: autocórica. $\mathbf{Z}$ ZOO, $\square$ ANE, AUT.

Figure 1. Percentile relation of the dispersion syndrome for species number (for all habits) and percentile relation of the dispersion syndrome for species abundance from each area, São Paulo State, Brazil. EM: Eugênio de Melo; TR: Tremembé; ZOO: zoochory; ANE: anemochory; AUT: autochory. Z ZOO, ANE, $\square$ AUT. 
as áreas, induziu a inversão entre a proporção de dispersão anemocórica e autocórica.

Baseado nos resultados obtidos por Giehl et al. (2007), a estratégia de dispersão autocórica pode estar vinculada a um favorecimento das espécies de Euphorbiaceae tolerantes aos períodos de inundação e pela relação expressiva desse tipo de síndrome com esta família (Almeida et al. 2008). Essa estratégia de dispersão também deve estar associada ao clima relativamente seco da região da calha do rio Paraíba do Sul (Cwa) que favorece a deiscência de frutos autocóricos (Mantovani \& Martins 1988, Tarola \& Morellato 2000).

Considerando os valores de abundância das espécies observa-se distinção notável entre as duas áreas amostradas na composição das populações de pioneiras e não pioneiras (figura 2). A área de EM expressa maior riqueza e abundância entre as não pioneiras, enquanto que em TR nota-se grande riqueza e abundância das espécies não pioneiras. Sebastiania commersoniana com 36 indivíduos em TR e 146 em EM foi a espécie que mais contribuiu para o incremento no valor referente às pioneiras, que acrescida de Alchornea triplinervia e Inga vera subsp. affinis provocaram a inversão observada em Eugênio de Melo. Isto indica muito provavelmente um estágio de desenvolvimento mais jovem para Eugênio de Melo em relação à Tremembé.

Apenas seis espécies consideradas não-pioneiras ocorrem no fragmento de Eugênio de Melo, sendo uma exclusiva na amostragem da área, Nectandra nitidula. Com relação às espécies pioneiras, também foram encontradas seis espécies ocorrendo em Eugênio de Melo, com Croton urucurana exclusiva desse fragmento e Annona cacans, Malouetia cestroides, Dendropanax cuneatus, Inga vulpina e Myrciaria floribunda exclusivas em Tremembé.

Coffea arabica e Syzygium jambos foram as únicas espécies exóticas observadas neste levantamento, exclusivas de Tremembé. A primeira, no sub-bosque e rara, e a segunda, mais expressiva no interior do fragmento, reflexo da introdução e dispersão dessa espécie na paisagem a partir do plantio em culturas caseiras e reflorestamento em áreas do entorno.

Quanto à amostragem fitossociológica total (Eugênio de Melo e Tremembé) foram registrados 720 indivíduos vivos, pertencentes a 52 espécies, 40 gêneros e 23 famílias, além de 33 indivíduos mortos.

As espécies com maiores IVI em EM foram Alchornea triplinervia, Sebastiania commersoniana e Inga vera subsp. affinis (tabela 2), perfazendo 72,3\% do total de indivíduos amostrados e representando $25 \%$ das espécies levantadas. As espécies indicadoras na amostragem dessa comunidade, com base nos resultados obtido pelo TWINSPAM, foram Nectandra nitidula, Alchornea triplinervia, Inga vera subsp. affinis, Picramnia sellowii e Coussapoa microcarpa.

A população de Alchornea triplinervia, em Eugênio de Melo, foi formada por indivíduos de grande porte e com as maiores alturas, ultrapassando o dossel uniforme composto basicamente por Sebastiania commersoniana. Entretanto, nota-se que esses indivíduos apresentam-se, em sua grande maioria, senescentes ou reproduzindo-se vegetativamente, com grandes diâmetros verticais a partir desses espécimes.
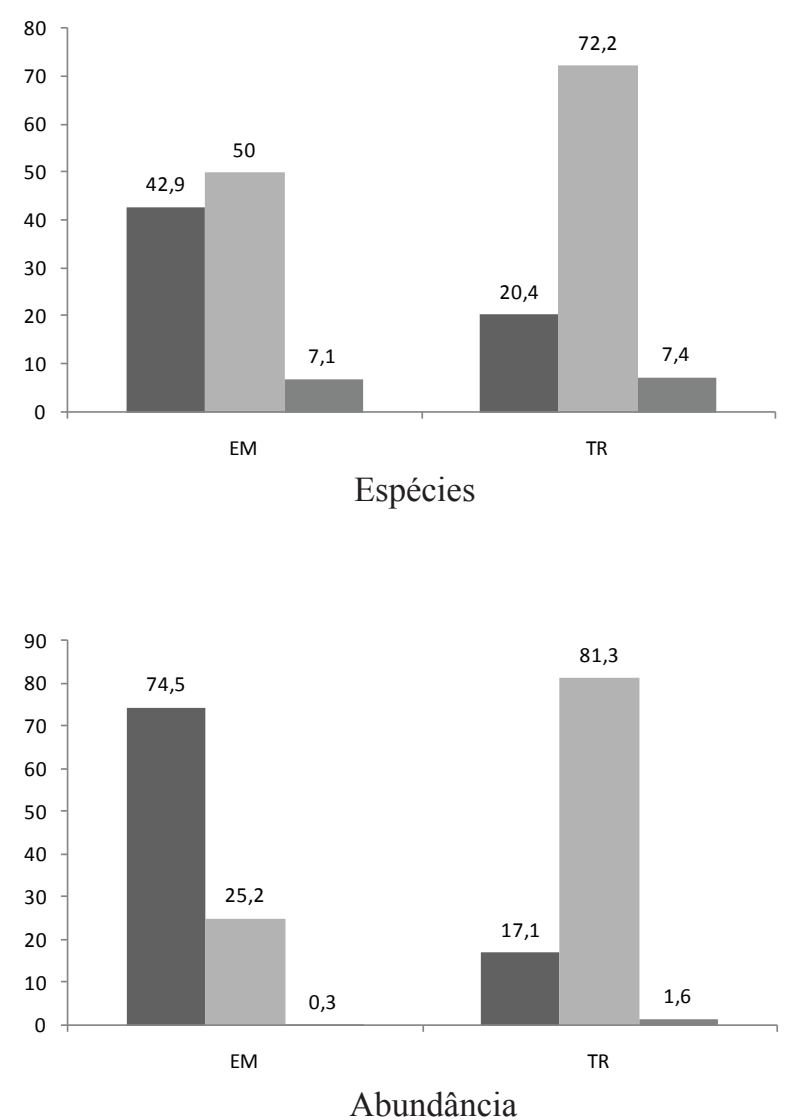

Figura 2. Porcentagem em relação ao número de espécies arbóreas coletadas e em relação à abundância de indivíduos arbóreos das amostragens fitossociológicas, pelas categorias sucessionais para cada uma das áreas, SP, Brasil. EM: Eugênio de Melo; TR: Tremembé; P: pioneiras; NP: não pioneiras; Indet.: indeterminadas. $\square$ P, $\square$ Indet., $\square$ NP.

Figure 2. Percentile relation of total tree species collected and the species colected and the abundance species for sucessional category from each area, São Paulo State, Brazil. EM: Eugênio de Melo; TR: Tremembé; P: Pionner; NP: non pionner, Indet.: indeterminate. $\square \mathrm{P}, \square$ Indet., $\square \mathrm{NP}$. 
Torres et al. (1992) recomendaram a utilização de Alchornea triplinervia para plantio em áreas de brejo na região de Campinas e Piracicaba considerando-a como uma espécie complementar e que, apesar de sua frequência nessas áreas, estão sempre associadas a solos com pouco encharcamento ou bem drenados (Toniato et al. 1998), podendo suportar inundações (Cardoso-Leite et al. 2004).

A predominância, observada em EM, de Sebastiania commersoniana no estrato dominante, tanto no dossel como no sub-bosque, já foi relatada para outras florestas inundáveis do Sul (Silva et al. 1992, Barddal et al. 2004, Budke et al. 2004, De Marchi \& Jarenkow 2008) e do Sudeste (Gibbs \& Leitão-Filho 1978). Callegaro et al. (2012) concluíram que a representatividade dessa espécie pode estar relacionada com o estádio secundário de sucessão florestal, sendo que Longhi et al. (2006) relataram ser essa a espécie indicadora desse estágio em um trecho de Floresta Ombrófila Mista.

Sebastiania commersoniana pertence ao mesmo gênero de outras espécies consideradas peculiares exclusivas de brejo como $S$. brasiliense, S. klotzschiana e S. edwalliana (Torres et al. 1992, Ivanauskas et al. 1997), sendo essas relacionadas a terrenos mais drenados. Essa espécie foi abundante em ambas as áreas apresentando ampla distribuição em toda a amostra.
Em TR, as três espécies mais relevantes com base nos valores de IVI foram Syagrus romanzoffiana, Handroanthus umbellatus e Sebastiania commersoniana que, somadas, compuseram $29,7 \%$ do total de indivíduos amostrados. Somando as nove espécies que obtiveram valores de IVI superiores a 10 (tabela 3) tem-se 61,6\% do total de indivíduos, com as seguintes espécies indicadoras dessa comunidade amostrada, resultantes de análises pelo TWINSPAM: Handroanthus umbellatus, Syagrus romanzoffiana, Andira anthelmia, Anadenanthera colubrina, Copaifera trapezifolia, Guapira opposita, Xylopia ochrantha, Neea pendulina, Acrocomia aculeata, Ixora brevifolia, Trichilia emarginata, Amaioua intermedia, Xylopia emarginata, Pseudobombax grandiflorum, Ouratea semiserrata e Malouetia cestroides.

Syagrus romanzoffiana, classificada como peculiar não exclusiva de brejo (Torres et al. 1992, Ivanauskas et al. 1997), é considerada de ampla distribuição, e pode desenvolver-se em terrenos secos até solos úmidos, brejosos ou inundáveis (Toniato et al. 1998, Bertani et al. 2001, Lorenzi 2002, Carvalho 2003). Para Emmons \& Gentry (1983 apud Sanchez et al. 1999), a alta abundância de palmeiras é uma característica comum em florestas neotropicais de baixada com solos ricos e úmidos, apesar de

Tabela 2. Espécies arbóreas em 0,2 ha de um fragmento de floresta aluvial da várzea do rio Paraíba do Sul, Eugênio de Melo, São José dos Campos, SP, Brasil, ordenadas de forma decrescente de IVI. NI: número de indivíduos; NS: número de subparcelas com ocorrência; DR: densidade relativa; FR: frequência relativa; DoR: dominância relativa; \%Ram: porcentagem de ramificados.

Table 2. Tree species in 0.2 hectare of an alluvial forest fragment in the floodplain of Paraíba do Sul River, Eugênio de Melo, São José dos Campos, São Paulo State, Brazil in decrescent order of IVI. NI: number of individuals; NS: subplots number; DR: relative density; FR: relative frequency; DoR: relative dominance; \%Ram: branched percentile.

\begin{tabular}{lrrrrrrc}
\hline Espécies & NI & NS & DR & FR & DoR & \%Ram & IVI \\
\hline Alchornea triplinervia (Spreng.) Müll. Arg. & 76 & 19 & 21,53 & 17,12 & 57,79 & 71,05 & 96,43 \\
Sebastiania commersoniana (Baill.) L.B. Sm. \& Downs. & 146 & 19 & 41,36 & 17,12 & 21,2 & 54,79 & 79,67 \\
Inga vera subsp. affinis (DC.) T.D. Penn. & 39 & 17 & 11,05 & 15,32 & 5,65 & 17,95 & 32,02 \\
Coussapoa microcarpa (Schott) Rizzini & 23 & 13 & 6,52 & 11,71 & 7,19 & 26,09 & 25,41 \\
Nectandra nitidula Nees & 27 & 9 & 7,65 & 8,11 & 1,59 & 29,63 & 17,35 \\
Chrysophyllum marginatum (Hook. \& Arn.) Radlk. & 15 & 12 & 4,25 & 10,81 & 2,26 & 40 & 17,32 \\
Picramnia sellowii Planch. & 16 & 12 & 4,53 & 10,81 & 1,29 & 50 & 16,64 \\
Eugenia florida DC. & 4 & 4 & 1,13 & 3,6 & 0,27 & 25 & 5,00 \\
Erythrina crista-galli L. & 2 & 2 & 0,57 & 1,8 & 1,38 & 50 & 3,75 \\
Myrcia multiflora (Lam.) DC. & 3 & 2 & 0,85 & 1,8 & 0,87 & 100 & 3,52 \\
Handroanthus umbellatus (Sond.) Mattos & 1 & 1 & 0,28 & 0,9 & 0,43 & 100 & 1,62 \\
Jacaranda sp. & 1 & 1 & 0,28 & 0,9 & 0,06 & 100 & 1,25 \\
\hline
\end{tabular}


Tabela 3. Listagem ordenada de forma decrescente de IVI das espécies arbóreas do levantamento realizado em 0,2 ha de um fragmento de floresta ombrófila densa aluvial da várzea do rio Paraíba do Sul, Tremembé, SP, Brasil. NI: número de indivíduos; NS: número de subparcelas com ocorrência; DR: densidade relativa; FR: frequência relativa; DoR: dominância relativa; \%R: porcentagem de indivíduos ramificados.

Table 3. Tree species in 0.2 hectare of an alluvial forest fragment in the floodplain of Paraíba do Sul River, Tremembé, São Paulo State, Brazil in decrescent order of IVI. NI: number of individuals; NS: number of subplots; DR: relative density; FR: relative frequency; DoR: relative dominance; \%R: percentile of branched individuals).

\begin{tabular}{|c|c|c|c|c|c|c|c|}
\hline Espécies & NI & NS & DR & FR & DoR & $\% \mathrm{R}$ & IVI \\
\hline Syagrus romanzoffiana (Cham.) Glassman & 41 & 17 & 11,17 & 8,1 & 22,14 & 0 & 41,41 \\
\hline Handroanthus umbellatus (Sond.) Mattos & 32 & 13 & 8,72 & 6,19 & 9,30 & 3,13 & 24,21 \\
\hline Sebastiania commersoniana (Baill.) L.B. Sm. \& Downs. & 36 & 10 & 9,81 & 4,76 & 6,98 & 13,89 & 21,55 \\
\hline Xylopia ochrantha Mart. & 24 & 14 & 6,54 & 6,67 & 4,15 & 4,17 & 17,35 \\
\hline Pseudobombax grandiflorum (Cav.) A. Robyns & 13 & 11 & 3,54 & 5,24 & 6,99 & 0 & 15,77 \\
\hline Neea pendulina Heimerl & 27 & 9 & 7,36 & 4,29 & 3,73 & 0 & 15,37 \\
\hline Ouratea semiserrata (Mart. ex Nees) Engl. & 26 & 13 & 7,08 & 6,19 & 1,35 & 3,85 & 14,63 \\
\hline Anadenanthera colubrina (Vell.) Brenan & 11 & 6 & 3,00 & 2,86 & 7,14 & 0 & 13,00 \\
\hline Eugenia florida DC. & 16 & 8 & 4,36 & 3,81 & 3,82 & 0 & 11,99 \\
\hline Copaifera trapezifolia Hayne & 10 & 7 & 2,72 & 3,33 & 2,87 & 0 & 8,93 \\
\hline Myrcia multiflora (Lam.) DC. & 13 & 7 & 3,54 & 3,33 & 1,38 & 15,38 & 8,26 \\
\hline Malouetia cestroides (Nees) Müll. Arg. & 10 & 5 & 2,72 & 2,38 & 3,09 & 0 & 8,19 \\
\hline Trichilia emarginata C. DC. & 9 & 8 & 2,45 & 3,81 & 1,16 & 0 & 7,42 \\
\hline Ixora brevifolia Benth. & 8 & 7 & 2,18 & 3,33 & 1,86 & 0 & 7,37 \\
\hline Guapira opposita (Vell.) Reitz & 10 & 6 & 2,72 & 2,86 & 1,27 & 0 & 6,85 \\
\hline Chrysophyllum marginatum (Hook. \& Arn.) Radlk. & 7 & 6 & 1,91 & 2,86 & 1,24 & 14,29 & 6,00 \\
\hline Syzygium jambos (L.) Alston & 4 & 3 & 1,09 & 1,43 & 2,99 & 25 & 5,50 \\
\hline Acrocomia aculeata (Jacq.) Lood. ex Mart. & 7 & 4 & 1,91 & 1,90 & 1,25 & 0 & 5,06 \\
\hline Andira anthelmia (Vell.) J.F. Macbr. & 5 & 5 & 1,36 & 2,38 & 1,22 & 0 & 4,96 \\
\hline Copaifera langsdorffii Desf. & 3 & 3 & 0,82 & 1,43 & 2,66 & 33,33 & 4,91 \\
\hline Amaioua intermedia Mart. ex Schult. \& Schult. f. & 5 & 4 & 1,36 & 1,9 & 0,53 & 20 & 3,79 \\
\hline Eugenia dodonaefolia Cambess. & 5 & 3 & 1,36 & 1,43 & 0,87 & 20 & 3,66 \\
\hline Xylopia emarginata Mart. & 4 & 4 & 1,09 & 1,9 & 0,39 & 0 & 3,38 \\
\hline Alchornea triplinervia (Spreng.) Müll. Arg. & 3 & 3 & 0,82 & 1,43 & 0,68 & 0 & 2,93 \\
\hline Pterocarpus rohrii Vahl & 1 & 1 & 0,27 & 0,48 & 2,16 & 0 & 2,91 \\
\hline Erythrina crista-galli $\mathrm{L}$. & 1 & 1 & 0,27 & 0,48 & 2,08 & 0 & 2,83 \\
\hline Inga vulpina Mart. ex Benth. & 3 & 3 & 0,82 & 1,43 & 0,23 & 0 & 2,48 \\
\hline Ecclinusa ramiflora Mart. & 4 & 1 & 1,09 & 0,48 & 0,89 & 0 & 2,45 \\
\hline Cariniana estrellensis (Raddi) Kuntze & 2 & 2 & 0,54 & 0,95 & 0,68 & 0 & 2,17 \\
\hline Magnolia ovata (A. St.-Hil.) Spreng. & 2 & 2 & 0,54 & 0,95 & 0,36 & 0 & 1,85 \\
\hline Myrciaria floribunda (H.West ex Willd.) O. Berg & 2 & 2 & 0,54 & 0,95 & 0,27 & 50 & 1,76 \\
\hline Inga subnuda subsp. luschnathiana (Benth.) T.D. Penn. & 2 & 2 & 0,54 & 0,95 & 0,24 & 0 & 1,74 \\
\hline Siparuna guianensis Aubl. & 2 & 2 & 0,54 & 0,95 & 0,23 & 50 & 1,73 \\
\hline Myrtaceae sp.1 & 2 & 2 & 0,54 & 0,95 & 0,18 & 0 & 1,68 \\
\hline Eugenia brevistyla D. Legrand & 2 & 2 & 0,54 & 0,95 & 0,08 & 0 & 1,58 \\
\hline Coussapoa microcarpa (Schott) Rizzini & 1 & 1 & 0,27 & 0,48 & 0,66 & 0 & 1,41 \\
\hline Qualea grandiflora Mart. & 1 & 1 & 0,27 & 0,48 & 0,65 & 0 & 1,39 \\
\hline
\end{tabular}


Tabela 3 (continuação)

\begin{tabular}{lccccccc}
\hline Espécies & NI & NS & DR & FR & DoR & $\%$ R & IVI \\
\hline Annona cacans Warm. & 1 & 1 & 0,27 & 0,48 & 0,55 & 0 & 1,30 \\
Indeterminada & 1 & 1 & 0,27 & 0,48 & 0,54 & 0 & 1,29 \\
Dendropanax cuneatus (DC) Decne. \& Planch. & 2 & 1 & 0,54 & 0,48 & 0,15 & 0 & 1,17 \\
Cecropia pachystachya Trec. & 1 & 1 & 0,27 & 0,48 & 0,23 & 0 & 0,98 \\
Inga vera subsp. affinis (DC.) T.D. Penn. & 1 & 1 & 0,27 & 0,48 & 0,23 & 0 & 0,98 \\
Posoqueria latifolia (Rudge) Roem. \& Schult. & 1 & 1 & 0,27 & 0,48 & 0,16 & 0 & 0,91 \\
Eugenia myrcianthes Nied. & 1 & 1 & 0,27 & 0,48 & 0,10 & 0 & 0,85 \\
Eugenia platysema O. Berg & 1 & 1 & 0,27 & 0,48 & 0,08 & 0 & 0,83 \\
Matayba juglandifolia (Camb.) Radlk. & 1 & 1 & 0,27 & 0,48 & 0,06 & 0 & 0,81 \\
Guarea macrophylla Vahl & 1 & 1 & 0,27 & 0,48 & 0,05 & 0 & 0,80 \\
Eugenia sp. & 1 & 1 & 0,27 & 0,48 & 0,04 & 0 & 0,79 \\
Zollernia ilicifolia Vogel & 1 & 1 & 0,27 & 0,48 & 0,04 & 0 & 0,79 \\
\hline
\end{tabular}

S. romanzoffiana também ser considerada indiferente às características nutricionais do solo (Carvalho 2003). A maior densidade e dominância dessa espécie foram registradas em floresta secundária no Parque Estadual das Fontes do Ipiranga, São Paulo, SP (Gomes \& Mantovani 2001). Acreditamos que também a alta luminosidade de áreas encharcadas tem favorecido o desenvolvimento da espécie caracterizando, assim, áreas alagadiças.

A espécie Handroanthus umbellatus, registrada com significativo valor de importância no estudo de Loures et al. (2007), é classificada como peculiar exclusiva das florestas de brejo por sua ocorrência preferencial em solos úmidos associados a várzeas inundáveis (Torres et al. 1992, Ivanauskas et al. 1997, Toniato et al. 1998, Lorenzi 2002), aqui sendo confirmada essa ocorrência.

Botrel et al. (2002), Carvalho et al. (2005) e Rocha et al. (2005) indicaram Sebastiania commersoniana, Trichilia emarginata, Myrcia multiflora, Eugenia florida e Copaifera langsdorffii como espécies indiferentes às variáveis ambientais. Entretanto, $S$. commersoniana ocorreu principalmente no Neossolo adjacente ao rio, no fragmento analisado por Botrel et al. (2002) e foi dominante em uma parcela mais alagada no estudo de Silva et al. (2007), que ressaltaram a tolerância dessa espécie ao encharcamento.

Outras duas espécies que apresentaram grande importância na amostragem em TR devido a alta dominância foram Anadenanthera colubrina e Pseudobombax grandiflorum, ambas consideradas secundárias (Bernacci et al. 2006), com a segunda associada a ambientes ripários (Lorenzi 2002, Carvalho 2003).

Ouratea semisserrata, Neea pendulina e Xylopia ochrantha tiveram ampla distribuição nas amostras, a primeira também registrada por Ivanauskas et al. (1997), que indicaram a espécie como complementar em áreas brejosas, porém não tendo ocorrência preferencial nesse ambiente, sendo sua presença na floresta de brejo considerada como simples eventualidade. Grande densidade e dominância dessa espécie foram registradas também em floresta secundária no Parque Estadual das Fontes do Ipiranga, São Paulo, SP (Gomes \& Mantovani 2001), dominante junto com espécies de dossel e emergentes. Puderam ser observados em TR muitos espécimes jovens dessas espécies distribuídas na paisagem, indicando o incremento delas na comunidade arbórea. As duas últimas são espécies que não constam em outros levantamentos em florestas inundáveis, mas foram muito abundantes em Tremembé.

Com relação à riqueza em famílias, Myrtaceae foi representada pelo maior número de espécies (11), seguida de Fabaceae (10), ambas constituídas apenas por árvores, Bromeliaceae, Rubiaceae (seis), Sapindaceae e Bignoniaceae, quatro espécies cada, correspondendo a $41,11 \%$ do valor total de espécies do levantamento florístico. As espécies classificadas como trepadeiras foram representadas principalmente pelas famílias Bignoniaceae, Malpighiaceae e Sapindaceae. As espécies arbustivas foram bem representadas nas famílias Melastomataceae e Rubiaceae. Todas as 14 famílias que ocorreram em Eugênio de Melo (EM) foram representadas também em Tremembé (TR). 
As famílias mais ricas na área de EM, considerando apenas os indivíduos arbóreos amostrados, foram Euphorbiaceae, Myrtaceae, Bignoniaceae e Fabaceae, representadas por duas espécies, perfazendo $77,1 \%$ do total de indivíduos amostrados e 67,6\% da riqueza. Em TR Fabaceae e Myrtaceae, com 10 espécies, foram as mais ricas, representando $49,8 \%$ do total de indivíduos amostrados; Annonaceae e Rubiaceae, com três espécies cada, somadas às duas famílias anteriores compuseram $55,8 \%$ da riqueza.

Pela análise de abundância, Euphorbiaceae, Lauraceae, Picramniaceae e Urticaceae foram predominantes na área de EM e corresponderam a $88,7 \%$ do total amostrado, enquanto Arecaceae, Annonaceae, Nyctaginaceae, Myrtaceae, Bignoniaceae e Malvaceae apresentaram-se com maior abundância em TR, perfazendo $46,9 \%$ do total de indivíduos.

As famílias Fabaceae, Myrtaceae e Rubiaceae são as famílias mais ricas em levantamentos de florestas de galeria, ciliares e ripárias do Estado de São Paulo (Bertoni \& Martins 1987, Bertani et al.2001, Teixeira \& Assis 2005, Aquino 2006, Teixeira \& Assis 2009), e são comumente associadas ao estrato intermediário dessas formações paulistas (Leitão-Filho 1982). Annonaceae, também destacada com maior riqueza por Teixeira \& Assis (2005), é considerada típica nas florestas de brejo do Estado (Leitão-Filho 1982), entretanto, sua representatividade em outros estudos dessas formações inundáveis não foi significativa.

Euphorbiaceae, Myrtaceae e Fabaceae, consideradas como as mais ricas em outros trabalhos no Estado de São Paulo (Gibbs \& Leitão-Filho 1978, Bertoni \& Martins 1987, Toniato et al. 1998, Aquino 2006), são comuns em florestas estacionais, sendo as duas primeiras, juntamente com Rubiaceae, as famílias com maior riqueza e IVI ocorrentes em florestas do domínio Atlântico do Sul e Sudeste do Brasil (Leitão-Filho 1982).

Os valores baixos em relação ao número de espécies totais sob condições espaciais e temporais mais intensas de inundação retratam florestas mais homogêneas, acarretando na dominância ecológica de determinadas populações de espécies peculiares como únicas representantes de determinadas famílias (Nogueira \& Schiavini 2003, Carvalho et al. 2005, Arieira \& Cunha 2006, Silva et al. 2007, Silva et al. 2009), como Calophyllum brasiliense (Clusiaceae), Protium almecega (Burseraceae) e Magnolia ovata (Magnoliaceae), observadas nos trabalhos de Ivanauskas et al. (1997) e Toniato et al. (1998).
Os valores dos parâmetros fitossociológicos, do índice de diversidade de Shannon e de equabilidade de Pielou, dentre outros comparáveis (tabela 4), evidenciam duas áreas distintas, sendo TR mais heterogênea e EM mais homogênea, com maior área basal e número de espécimes ramificados.

O valor pouco superior da área basal de Eugênio de Melo em relação à Tremembé pode estar relacionado com maior grau de influência hídrica nessa primeira área (Gianotti 1988, Bertani et al. 2001, Carvalho et al. 2005, Lopes \& Schiavini 2007), bem como pela presença de alguns indivíduos grandes de Alchornea triplinervia. Um dos fatores que também deve ter contribuído para esse resultado foi o elevado número de espécimes de grande porte e ramificados em EM, com cerca de dez vezes mais indivíduos ramificados em EM do que em TR. Este último dado pode estar representando um histórico de cortes raso para o uso do solo ou estar relacionado com uma dinâmica peculiar dessa formação.

A baixa diversidade e riqueza em EM foram os fatores fundamentais para a dissimilaridade entre as duas áreas amostradas, entretanto, 75\% das espécies das árvores quantificadas em EM (87,5\% do total de indivíduos) foram encontradas em TR. A heterogeneidade da flora em TR pode ser verificada pela dissimilaridade entre as subparcelas dessa amostra (figura 3).

A densidade total estimada para um hectare (ha) na amostra conjunta (Tremembé e Eugênio de Melo) foi de 1.882,5 ind ha- ${ }^{-1}$, semelhante ao resultado obtido

Tabela 4. Dados estruturais obtidos entre as amostras de Eugênio de Melo (EM) e Tremembé (TR), SP, Brasil.

Table 4. Structure data from Eugênio de Melo (EM) and Tremembé (TR) samples, São Paulo State, Brazil.

\begin{tabular}{lcc}
\hline & EM & TR \\
\hline Número de indivíduos & 353 & 367 \\
Mortos & 8 & 25 \\
Riqueza ( ${ }^{\text {o }}$ de espécies) & 12 & 49 \\
Densidade relativa (ind ha $\left.{ }^{-1}\right)$ & 1.765 & 1.835 \\
Altura máxima (m) & 13,5 & 18 \\
Diâmetro máximo (cm) & 53,2 & 37,4 \\
Indivíduos ramificados (\%) & 49,9 & 4,6 \\
Área Basal $\left(\mathrm{m}^{2} \mathrm{ha}^{-1}\right)$ & 25,4 & 24,35 \\
Volume (m $\left.\mathrm{ha}^{-1}\right)$ & 48,02 & 55,22 \\
Diversidade $\left(\mathrm{H}^{\prime}\right)$ & 1,74 & 3,25 \\
Equabilidade & 0,701 & 0,835 \\
\hline
\end{tabular}


por Giampietro (2005) em Assis (1.897 ind ha ${ }^{-1}$ ). A relação existente entre a riqueza e o total de indivíduos amostrados do presente trabalho (0,4 ha) aproximou-se dos estudos de Durigan (1994), em Assis, e Marques et al. (2003), em Brotas.

$\mathrm{O}$ índice de diversidade $\left(\mathrm{H}^{\prime}\right)$ do total amostrado foi de 3,05 , próximo dos resultados obtidos por Giampietro (2005), em Assis $(2,98)$ e Teixeira \& Rodrigues (2006), em Cristais Paulista (3,17). Eugênio de Melo apresentou valor de diversidade de 1,74, aproximando-se do estudo de Carboni (2007) em Bauru, enquanto em Tremembé a diversidade foi de 3,25, com valores semelhantes aos de Durigan (1994), em Marília $(3,44)$ e Gomes et al. (2004), em Brotas $(3,37)$. Estas diferenças parecem estar relacionadas também ao estágio de desenvolvimento dessas florestas, com maiores valores de Shannon para áreas de desenvolvimento mais antigo e menores valores para áreas mais recentes, assim como com ao grau de encharcamento do substrato.

A estrutura florestal do trecho de Eugênio de Melo foi composta por indivíduos com alturas inferiores às da área de Tremembé, porém, com diâmetros superiores (figura 4).

$\mathrm{Na}$ área de EM, 67,8\% dos espécimes amostrados apresentaram altura entre seis e nove metros, com 43,9\% deste total formado por Sebastiania commersoniana e $20 \%$ de Alchornea triplinervia
( $75 \%$ da riqueza amostrada estiveram representadas nessa classe). Indivíduos com alturas inferiores formaram 19\% do total amostrado, nos quais Eugenia florida e Jacaranda sp. foram exclusivas, com $44,6 \%$ deste total composto por $S$. commersoniana, $9,5 \%$ de Picramnia sellowii e $9,5 \%$ de mortos $(83,3 \%$ da riqueza amostrada estiveram representadas nessa classe).

Valores superiores a nove metros representaram 13,3\% do total amostrado, nos quais Erythrina crista-galli e Handroanthus umbellatus foram exclusivas, com $62,5 \%$ deste total formado por A. triplinervia e $15,6 \%$ de Inga vera subsp. affinis (50\% da riqueza amostrada estiveram representadas nessa classe). Destacaram-se com os maiores valores em altura Coussapoa microcarpa (13,5 e 12,5 m), A. triplinervia (13 e 11,5 m) e I. vera subsp. affinis (11,5 e $11 \mathrm{~m})$.

Dessa forma, observa-se o predomínio de $S$. commersoniana nos estratos inferiores a nove metros, enquanto $A$. triplinervia destacou-se nos estratos superiores.

Com relação às alturas em Tremembé, 57,4\% dos indivíduos amostrados varia entre 5,5 e 10,5 metros, sendo $11,3 \%$ deste total representado por Sebastiania commersoniana, 9,7\% de Handroanthus umbellatus, $7,7 \%$ de Neea pendulina, $6,1 \%$ de Xylopia ochrantha e $6,1 \%$ de mortos $(71,4 \%$ do total de espécies). Indivíduos com alturas inferiores

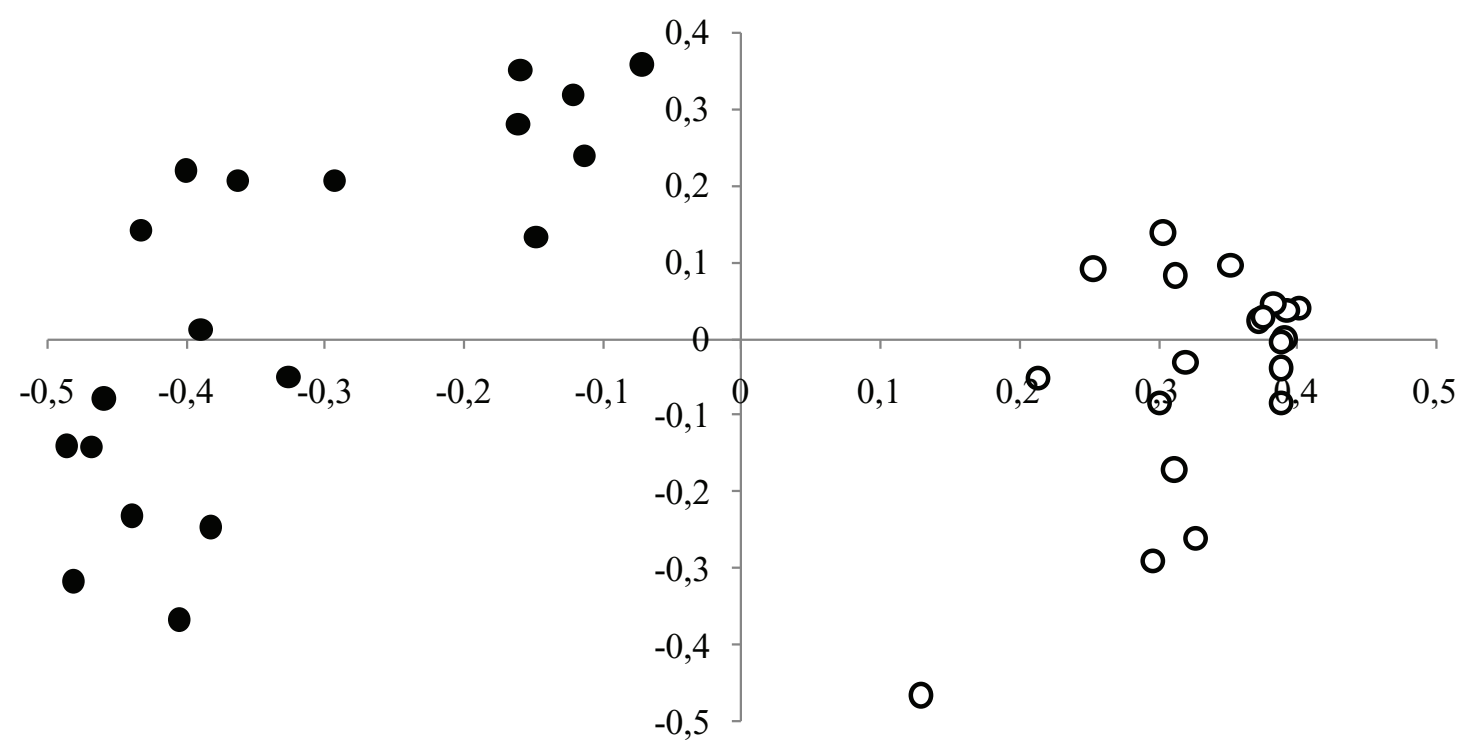

Figura 3. Ordenação pela PCO, representando a dissimilaridade entre as subparcelas $(10 \times 10 \mathrm{~m})$ de Tremembé (pontos escuros) e Eugênio de Melo (pontos claros), SP, Brasil. oEM, •TR.

Figure 3. Ordenation from PCO, showing dissimilarity among the subplots $(10 \times 10 \mathrm{~m})$ of Tremembé (black points) and Eugênio de Melo (white points), São Paulo State, Brasil. o EM, • TR. 
representaram $11,7 \%$ do total amostrado, com 30,9\% deste valor representado por Ouratea semiserrata e $16,4 \%$ de indivíduos mortos $(34,7 \%$ do total de espécies). Alturas superiores agruparam 30,9\% do total de indivíduos, nos quais Pterocarpus rohrii, Qualea grandiflora e Coussapoa microcarpa foram exclusivas, com $32,6 \%$ dessa classe representada por Syagrus romanzoffiana, 7,9\% por Anadenanthera colubrina e 7,9\% por Xylopia ochrantha $(41,8 \%$ das espécies amostradas nesta área estiveram representadas nessa classe de altura).

Os indivíduos de maior porte foram: Anadenathera colubrina $(18 \mathrm{~m})$, Syagrus romanzoffiana $(17 \mathrm{~m})$, Handroanthus umbellatus (16 m), Sizygium jambos $(15,5 \mathrm{~m})$, Xylopia ochrantha, Copaifera trapezifolia (14 m cada) e Pterocarpus rohrii $(13,5 \mathrm{~m})$. Essas espécies representaram aproximadamente 1/3 do total de indivíduos amostrados em Tremembé, demonstrando que as áreas paludosas constituem florestas relativamente baixas.

Pode ser observada nesta amostragem, a representatividade dos espécimes de Sebastiania commersoniana na mesma faixa de altura em que foram significativos na área de Eugênio de Melo. Nota-se o predomínio de Ouratea semiserrata no sub-bosque e a participação significativa de Syagrus romanzoffiana no dossel dessa formação. Os indivíduos emergentes foram representados por
S. romanzoffiana, A. colubrina e $H$. umbellatus, totalizando 18 indivíduos, sendo estas as únicas espécies que ocorreram em todas as classes de altura.

Quanto aos resultados dos diâmetros, 57,3\% dos indivíduos em EM apresentaram medidas entre 5 e $10 \mathrm{~cm}$ e 79,4\% com espécimes de diâmetro de 5 a $15 \mathrm{~cm}$. Com diâmetros inferiores foram $4 \%$, e 16,6\% com valores superiores a $15 \mathrm{~cm}$, sendo que os valores máximos foram verificados em Alchornea triplinervia $(40,74 \mathrm{~cm})$ e Coussapoa microcarpa $(36,44 \mathrm{~cm})$. Valores relativamente superiores em área basal, assim como o predomínio no estrato superior, já foram relatados para A. triplinervia (Ivanauskas et al. 1997, Guilherme et al. 2004).

Em relação aos diâmetros de TR, 50,3\% dos indivíduos amostrados apresentaram 5 a $11,25 \mathrm{~cm}$, sendo $5,1 \%$ registrando valores inferiores, enquanto $44,6 \%$ apresentaram valores superiores a $11,25 \mathrm{~cm}$. Foram registrados os maiores diâmetros para Pseudobombax grandiflorum, Pterocarpus rohrii, Erythrina crista-galli, Handroanthus umbellatus e Anadenanthera colubrina.

Os indivíduos ramificados corresponderam a $50 \%$ do total amostrado na área de EM, com destaque para Alchornea triplinervia, com 71,05\% de seus representantes ramificados, e Sebastiania commersoniana, com 54,79\%. Na área de TR, 5\% do total de indivíduos amostrados eram ramificados e
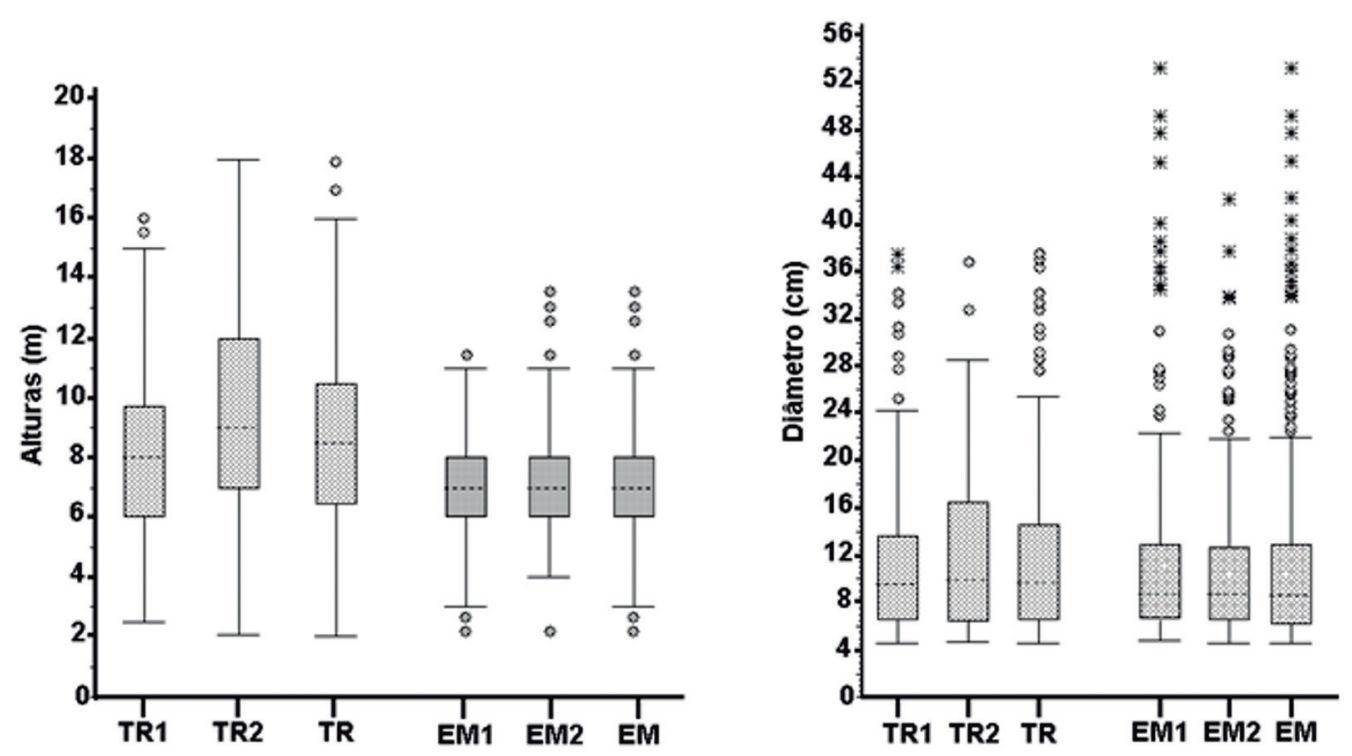

Figura 4. Gráfico boxplot de alturas e diâmetros comparativos entre as amostras de 0,2 ha de Tremembé (TR) e Eugênio de Melo (EM), SP, Brasil e das suas respectivas parcelas (0,1 ha) TR1, TR2, EM1 e EM2. Metodologia.

Figure 4. Boxplot graphic of comparative heights and diameters between the 0.2 hectare of Tremembé (TR) and Eugênio de Melo (EM), São Paulo State, Brazil and of their respective samples (0.1 hectare) TR1, TR2, EM1 and EM2. 
foram representados pelas espécies Sizygium jambos, Eugenia dodonaeifolia, S. commersoniana, Siparuna guianensis e um espécime morto.

Os resultados permitem concluir que, em todos os aspectos, exceto no número de ramificações, Eugênio de Melo apresentou menor complexidade que a formação de Tremembé.

A amostra de Tremembé (TR) foi a mais rica em espécies, apresentando os maiores valores em altura, indivíduos mortos, densidade, diversidade e dissimilaridade entre subparcelas, apresentando-se como uma formação arbórea mais heterogênea em comparação a Eugênio de Melo (EM), que por sua vez obteve maiores valores em área basal e de número de indivíduos ramificados. Isso pode indicar um estágio de regeneração mais recente em EM do que em TR. Croton urucurana e Nectandra nitidula foram espécies exclusivas na área de EM, onde Alchornea triplinervia tem participação significativa na composição dos estratos superiores e nos valores em área basal. Syagrus romanzoffiana, Handroanthus umbellatus e Anadenanthera colubrina apresentaram altos valores em importância e estiveram presentes em todos os estratos de altura em TR.

As 20 espécies mais importantes considerando a amostragem conjunta das áreas de Eugênio de Melo (EM) e Tremembé (TR), e que devem ser consideradas para o plantio em áreas de compensação ambiental pelas mineradoras de areia da região, juntamente com as demais espécies listadas, foram: Alchornea triplinervia, Sebastiania commersoniana, Syagrus romanzoffiana, Inga vera subsp. affinis, Handroanthus umbellatus, Coussapoa microcarpa, Chrysophyllum marginatum, Xylopia ochrantha, Pseudobombax grandiflorum, Eugenia florida, Neea pendulina, Ouratea semiserrata, Nectandra nitidula, Anadenanthera colubrina, Picramnia sellowi, Myrcia multiflora, Copaifera trapezifolia, Trichilia emarginata, Ixora brevifolia e Malouetia cestroides.

A espécie Sebastiania commersoniana foi abundante no estrato intermediário em ambas as áreas apresentando valores de importância significativos tanto em Eugênio de Melo (EM) e Tremembé (TR), destacando-se como característica dessas formações aluviais.

O aprofundamento de estudos envolvendo a caracterização das florestas da várzea do médio vale superior do rio Paraíba do Sul, não apenas florísticos e fitossociológicos, como também envolvendo a dinâmica sucessional e suas relações com os fatores edáficos/hidrológicos, são fundamentais para a melhoria de trabalhos de restauração florestal e na manutenção dos recursos hídricos da região.

\section{Agradecimentos}

AoCurso de Pós-Graduação do Instituto de Botânica; ao Conselho Nacional de Desenvolvimento Científico e Tecnológico $(\mathrm{CNPq})$, pela bolsa e financiamento do trabalho de campo (Processo 482050/2011-0); à Dra. Inês Cordeiro, Dr. João Aurélio Pastore, Msc. Osny Tadeu de Aguiar, Dr. João Batista Baitello e Msc. André Luiz Gaglioti, pelo auxílio na identificação do material coletado; ao Dr. Eduardo Pereira Cabral Gomes, Dr. Waldir Mantovani e Dra. Natália Macedo Ivanauskas, pelas críticas e sugestões.

\section{Literatura citada}

Aquino, C. 2006. Avaliação de três formas de enriquecimento em área ciliar revegetada junto ao rio Mogi-Guaçu, SP. Dissertação de Mestrado, Universidade Estadual Paulista "Júlio de Mesquita Filho", Rio Claro.

Arieira, J. \& Cunha, C.N. 2006. Fitossociologia de uma floresta inundável monodominante de Vochisia divergens Pohl (Vochysiaceae), no Pantanal Norte, MT, Brasil. Acta Botanica Brasilica 20: 569-580.

Barddal, M.L., Roderjan, C.V., Galvão, E. \& Curcio, G.R. 2004. Caracterização florística e fitossociológica de um trecho sazonalmente inundável de floresta aluvial, em Araucária, PR. Ciência Florestal 14: 399-412.

Batista, G.T., Catelani, C.S., Reis, B.J. \& Targa, M.S. 2010. Influência das cavas de extração de areia no balanço hídrico do vale do Paraíba do Sul. http://www.comiteps.sp.gov.br/ docs/cavas_nas_areia.pdf(acesso em 14.06.2011).

Bernacci, L.C., Franco, G., Arbocz, G., Catharino, E.L.M., Durigan, G. \& Metzger, J.P. 2006. O efeito da fragmentação florestal na composição e riqueza de árvores na região da Reserva Florestal do Morro Grande (Planalto de Ibiúna, SP). Revista do Instituto Florestal 18: 121-166.

Bertani, D.F., Rodrigues, R.R., Batista, J.L.F. \& Shepherd, G.J. 2001. Análise da heterogeneidade florística e estrutural em uma floresta ribeirinha. Revista Brasileira de Botânica 24: 11-23.

Bertoni, D.W. \& Martins, F.R. 1987. Composição florística de uma floresta ripária na Reserva Estadual de Porto Ferreira, SP. Acta Botanica Brasilica 1: 17-26.

Botrel, R., Oliveira Filho, A.T., Rodrigues, L.A. \& Curi, N. 2002. Influência do solo e topografia sobre as variações da composição florística e estrutura da comunidade arbóreo-arbustiva de uma floresta estacional semidecidual em Ingaí, MG. Revista Brasileira Botânica 25: 195-213. 
Budke, J.C., Giehl, E.L.H., Athayde, E.A., Eisinger, S.M. \& Záchia, R.A. 2004. Florística e fitossociologia do componente arbóreo de uma floresta ribeirinha, arroio Passo das Tropas, Santa Maria, RS, Brasil. Acta Botanica Brasilica 18: 399-412.

Callegaro, R.M., Longhi, S.J., Araújo, A.C.B., Kanieski, M.R., Floss, P.A. \& Gracioli, C.R. 2012. Estrutura do componente arbóreo de uma floresta estacional ripária em Jaguari, RS. Ciência Rural 42: 305-311.

Campanili, M. \& Schäffer, W.B. 2010. Mata Atlântica: patrimônio nacional dos brasileiros. Ministério do Meio Ambiente. Secretaria de Biodiversidade e Florestas. Núcleo Mata Atlântica e Pampa (Biodiversidade 23). MMA, Brasília.

Carboni, M. 2007. Composição, estrutura e diversidade vegetal de uma floresta estacional semidecídua ribeirinha com influência fluvial permanente (mata de brejo) em Bauru - SP. Dissertação de Mestrado, Universidade Estadual Paulista "Júlio de Mesquita Filho", Bauru.

Cardoso-Leite, E., Covre, T.B., Ometto, R.G., Cavalcanti, D.C. \& Pagani, M.I. 2004. Fitossociologia e caracterização sucessional de um fragmento de mata ciliar, em Rio Claro/SP, como subsídio à recuperação da área. Revista Instituto Florestal 16: 31-41.

Carvalho, D.A., Oliveira-Filho, A.T., Vilela, E.A., Curi, N., Van Den Berg, E., Fontes, M.A.L. \& Botezelli, L. 2005. Distribuição de espécies arbóreo-arbustivas ao longo de um gradiente de solos e topografia em um trecho de floresta ripária do Rio São Francisco em Três Marias, MG, Brasil. Revista Brasileira de Botânica 28: 329-345.

Carvalho, P.E.R. 2003. Espécies arbóreas brasileiras. EMBRAPA Florestas, Colombo.

CEPAGRI. 2011. Centro de pesquisas meteorológicas e climáticas aplicadas à agricultura. UNICAMP, Campinas (SP). http://www.cpa.unicamp.br/outrasinformacoes/clima-dos-municipios-paulistas.html (acesso em 14.06.2011).

De Marchi, T.C. \& Jarenkow, J.A. 2008. Estrutura do componente arbóreo de mata ribeirinha no rio Camaquã, município de Cristal, Rio Grande do Sul, Brasil. Iheringia 63: 241-248.

Durigan, G. 1994. Florística, fitossociologia e produção de folhedo em matas ciliares da região oeste do estado de São Paulo. Tese de Doutorado, Universidade Estadual de Campinas, Campinas.

Forzza, R.C., Stehmann, R.C., Nadruz, M., Costa, A., Carvalho Jr., A.A., Peixoto, A.L., Walter, B.M.T., Bicudo, C., Moura, C.W.N., Zappi, D., Costa, D.P., Lleras, E., Martinelli, G., Lima, H.C., Prado, J., Baumgratz, J.F.A., Pirani, J.R., Sylvestre, L.S., Maia, L.C., Lohmann, L.G., Paganucci, L., Alves, M.V.S., Silveira, M., Mamede, M.C.H., Bastos, M.N.C., Morim, M.P., Barbosa, M.R., Menezes, M., Hopkins, M., Evangelista, P.H.L., Goldenberg, R., Secco, R., Rodrigues, R.S., Cavalcanti, T. \& Souza, V.C. 2010. Lista das espécies da flora do Brasil. Jardim Botânico do Rio de Janeiro, RJ. http://floradobrasil. jbrj.gov.br/2010 (acesso em 15.03.2013).
Giampietro, R.L. 2005. Modificações na estrutura e composição florística de matas ciliares na região do médio Paranapanema (1992-2004). Dissertação de Mestrado, Universidade de São Paulo, São Paulo.

Gianotti, E. 1988. Composição florística e estrutura da vegetação de cerrado e de transição entre cerrado e mata ciliar da Estação Experimental de Itirapina (SP). Dissertação de Mestrado, Universidade Estadual de Campinas, Campinas. http://www.bibliotecadigital. unicamp.br/document $/$ ? code $=000048540$ (acesso em 22.11.2011).

Gibbs, P.E. \& Leitão Filho, H.F. 1978. Floristic composition of an area of gallery forest near MogiGuaçu, State of São Paulo, SE Brazil. Revista Brasileira de Botânica 1: 151-156.

Gomes, B.Z., Martins, F.R. \& Tamashiro, J.Y. 2004. Estrutura do cerradão e da transição entre cerrado e floresta paludícula num fragmento da International Paper do Brasil Ltda., em Brotas, SP. Revista Brasileira de Botânica 27: 249-262.

Gomes, E.C.P. \& Mantovani, W. 2001. Size structure of six tree populations in a subtropical rain forest in southeastern Brazil. Naturalia 26: 131-158.

Guilherme, F.A.G., Morellato, L.P.C. \& Assis, M.A. 2004. Horizontal and vertical tree community structure in a lowland Atlantic Rain Forest, Southeastern Brazil. Revista Brasileira de Botânica 27: 725-737.

Hueck, K. 1972. As florestas da América do Sul. Editora Universidade de São Paulo, São Paulo.

IBGE. 1992. Manual técnico da vegetação brasileira. Instituto Brasileiro de Geografia e Estatística, Rio de Janeiro.

Ivanauskas, N.M., Rodrigues, R.R. \& Nave, A.G. 1997. Aspectos ecológicos de um trecho de floresta em Itatinga, SP: florística, fitossociologia e seletividade de espécies. Revista Brasileira de Botânica 20: 139-153.

Leitão Filho, H.F. 1982. Aspectos taxonômicos das florestas do Estado de São Paulo. Silvicultura em São Paulo 16-A: 197-206.

Longhi, S.J., Brena, D.A., Gomes, J.F., Narvaes, I.S., Berger, G. \& Soligo, A.J. 2006. Classificação e caracterização de estágios sucessionais em remanescentes de floresta ombrófila mista na FLONA de São Francisco de Paula, RS, Brasil. Ciência Florestal 16: 113-125.

Lopes, S. de F. \& Schiavini, I. 2007. Dinâmica da comunidade arbórea de mata de galeria da Estação Ecológica do Panga, Minas Gerais, Brasil. Acta Botanica Brasilica 21: 249-261.

Lorenzi, H. 2002. Árvores brasileiras: manual de identificação e cultivo de plantas arbóreas nativas do Brasil. v.1, 4 ed. Instituto Plantarum, Nova Odessa.

Loures, L., Carvalho, D.A., Machado, E.L.M \& Marques, J.J.G.S. 2007. Florística, estrutura e características do solo de um fragmento de floresta paludosa no sudeste do Brasil. Acta Botanica Brasilica 21: 885-896. 
Marques, M.C.M., Silva, S.M. \& Salino, A. 2003. Florística e estrutura do componente arbustivo-arbóreo de uma floresta higrófila da bacia do rio Jacaré-Pepira, SP, Brasil. Acta Botanica Brasilica 17: 495-506.

Moura, C.A., Jimenez-Rueda, J.R., Coelho, J.O.M. 2006. O processo pedogenético no domínio tropical atlântico - o exemplo do Vale do Paraíba do Sul/SP. In: Anais do $6^{\circ}$ Simpósio Nacional de Geomorfologia, Goiânia, pp. 1-10.

Nogueira, M.F. \&Schiavini, I. 2003. Composição florística e estrutural da comunidade arbórea de uma mata de galeria inundável em Uberlândia, MG, Brasil. Bioscience Journal 19: 89-98.

Pijl, L. van der. 1982. Principles of dispersal in higher plants. Springer-Verlag, Berlim.

Rocha, C.T.V., Carvalho, D.A., Fontes, M.A.S., Oliveira Filho, A.T., Van Den Berg, E. \& Marques, J.J.G.S.M. 2005. Comunidade arbórea de um continuum entre floresta paludosa e de encosta em Coqueiral, Minas Gerais, Brasil. Revista Brasileira de Botânica 28: 203-217.

Rodrigues, R.R. \& Nave, A.G. 2001. Heterogeneidade florística das matas ciliares. In: R.R. Rodrigues \& H.F. Leitão Filho (orgs.). Matas ciliares: conservação e recuperação. EDUSP: FAPESP, São Paulo, pp. 45-71.

Sanchez, M., Pedroni, F., Leitão-Filho, H.F. \& César, O. 1999. Composição florística de um trecho de floresta ripária na Mata Atlântica em Picinguaba, Ubatuba, SP. Revista Brasileira de Botânica 22: 31-42.

São Paulo (Estado). 1999. Resolução SMA 28, de 22 de setembro de 1999. http://www.cetesb.sp.gov.br/ licenciamento/legislacao/estadual/resolucoes/1999 Res_SMA_28.pdf (acesso em 05.10.2011).

Shepherd, G. 2010. FITOPAC 2.1: Manual do usuário. Universidade Estadual de Campinas, Campinas.

Silva, A.C., Van Den Berg, E., Higuchi, P., OliveiraFilho, A.T., Marques, J.J. de S.M., Appolinário, V., Pifano, D.S., Ogusuku, L.M. \& Nunes, M.H. 2009. Florística e estrutura da comunidade arbórea em fragmentos de floresta aluvial em São Sebastião da Bela Vista, Minas Gerais, Brasil. Revista Brasileira de Botânica 32: 283-297.
Silva, A.C., Van Den Berg, E., Higuchi, P. \& Oliveira Filho, A.T.O. 2007. Comparação florística de florestas inundáveis das regiões Sudeste e Sul do Brasil. Revista Brasileira de Botânica 30: 257-269.

Silva, S.M., Silva, F.C., Vieira, A.O.S., Nakajima, J.N., Pimenta, J.A. \& Colli, S. 1992. Composição florística e fitossociológica do componente arbóreo das florestas ciliares da Bacia do Rio Tibagi, Paraná: 2. Várzea do rio Bitumirim, Município de Ipiranga, PR. Revista do Instituto Florestal 4: 192-198.

Siqueira, M. \& Durigan, G. 2007. Modelagem da distribuição geográfica de espécies lenhosas de cerrado no Estado de São Paulo. Revista Brasileira de Botânica 30: 233-243.

SMA. 1999. Conhecer para conservar: as unidades de conservação do Estado do São Paulo. Secretaria de Estado do Meio Ambiente, São Paulo.

Stefanello, D., Ivanauskas, N.M., Martins, S.V., Silva, E. \& Kunz, S.H. 2010. Síndromes de dispersão de diásporos das espécies de trechos de vegetação ciliar do rio das Pacas, Querência - MT. Acta Amazonica 40: 141-150.

Teixeira, A.P. \& Assis, M.A. 2005. Caracterização florística e fitossociológica do componente arbustivo-arbóreo de uma floresta paludosa no Município de Rio Claro (SP), Brasil. Revista Brasileira de Botânica 28: 467-476.

Teixeira, A.P. \& Assis, M.A. 2009. Relação entre heterogeneidade ambiental e distribuição de espécies em uma floresta paludosa no município de Cristais Paulista, SP, Brasil. Acta Botanica Brasilica 23: 843-853.

Teixeira, A.P. \& Rodrigues, R.R. 2006. Análise florística do componente arbustivo-arbóreo de uma floresta de galeria no município de Cristais Paulista, SP, Brasil. Acta Botanica Brasilica 20: 803-813.

Toniato, M.T.Z., Leitão filho, H.F. \& Rodrigues, R.R. 1998. Fitossociologia de um remanescente de floresta higrófila (Mata de Brejo) em Campinas, São Paulo. Revista Brasileira de Botânica 21: 197-210.

Torres, R.B., Mathes, L.A.F., Rodrigues, R.R. \& LeitãoFilho, H.F. 1992. Lista de espécies florestais nativas para o plantio em área de brejo. O Agronômico 44: 1-2.

Valladares, G.S., Marin F.R., Oshiro O.T. \& Guimarães M. 2004. Uso de imagens de radar na estimativa da temperatura do ar. EMBRAPA, Campinas. 